\title{
Perfluoroalkane Functionalization of NU-1000 via Solvent-Assisted Ligand Incorporation: Synthesis and $\mathrm{CO}_{2}$ Adsorption Studies
}

Pravas Deria, ${ }^{\dagger}$ Joseph E. Mondloch, ${ }^{\dagger}$ Emmanuel Tylianakis, ${ }^{\dagger, \grave{\dagger}}$ Pritha Ghosh, ${ }^{\dagger}$ Wojciech Bury, ${ }^{\dagger, \S}$ Randall Q. Snurr, ${ }^{* \dagger}$ Joseph T. Hupp, ${ }^{* \dagger}$ and Omar K. Farha ${ }^{*, \dagger}$

${ }^{\dagger}$ Departments of Chemistry and Chemical and Biological Engineering, Northwestern University, 2145 Sheridan Road, Evanston, Illinois 60208, United States

${ }^{\ddagger}$ Materials Science and Technology Department, University of Crete, P.O. Box 2208, 71409 Heraklion, Crete, Greece

${ }^{\S}$ Department of Chemistry, Warsaw University of Technology, Noakowskiego 3, 00-664 Warsaw, Poland

\section{Supporting Information}

ABSTRACT: A new functionalization technique, solventassisted ligand incorporation (SALI), was developed to efficiently incorporate carboxylate-based functionalities in the Zr-based metal-organic framework, NU-1000. Unlike previous metal node functionalization strategies, which utilize dative bonding to coordinatively unsaturated metal sites, SALI introduces functional groups as charge compensating and strongly bound moieties to the $\mathrm{Zr}_{6}$ node. Utilizing SALI, we have efficiently attached perfluoroalkane carboxylates of various chain lengths $\left(\mathrm{C}_{1}-\mathrm{C}_{9}\right)$ on the $\mathrm{Zr}_{6}$ nodes of NU-1000. These fluoroalkane-functionalized mesoporous MOFs, termed herein SALI- $\boldsymbol{n}$, were studied experimentally and theoretically as potential $\mathrm{CO}_{2}$ capture materials.

T etal-organic frameworks (MOFs) constitute a rapidly 1 growing class of solid-state compounds. They are built up from multitopic organic linkers and metal-based nodes which are interconnected by coordination bonds of moderate strength. ${ }^{1}$ From a functional materials perspective, due to their chemical diversity and high surface area, ${ }^{2}$ MOFs have garnered tremendous interest for many practical applications including gas storage and separation, ${ }^{3}$ chemical catalysis, ${ }^{4}$ sensing, ${ }^{5}$ conductivity, ${ }^{6}$ and light harvesting. ${ }^{7}$ Given the highly modular nature of MOFs, the introduction of chemical functionality should be straightforward (at least in comparison to many other solid-state materials). Unfortunately, de novo syntheses (i.e., one-pot solvothermal syntheses) often encounter problems associated with linker solubility, linker stability, and/or the formation of undesirable structures or side products (e.g., the coordination of metal ions to the functionalized linker). ${ }^{8}$

Postsynthesis incorporation of desired functionality within a given MOF structure has proven to be a key strategy in overcoming many synthetic challenges associated with de novo MOF preparation. ${ }^{8}$ Some of the most attractive strategies include functionalization at the metal node (via dative bonding), ${ }^{9}$ covalent modification of the organic linker, ${ }^{10}$ and solvent-assisted linker exchange (SALE) ${ }^{11}$ which involves completely exchanging one organic linker for another. In the context of functional materials, MOFs with high chemical and thermal stability are desirable. Among the various metal-based nodes, MOFs constructed from oxophilic $\mathrm{Zr}^{\mathrm{IV}}{ }_{6}$ nodes have high thermal (up to $500{ }^{\circ} \mathrm{C}$ ), chemical $(\mathrm{pH} 1-10),{ }^{12}$ and mechanical stability. ${ }^{12,13}$ Recently, we ${ }^{14}$ and others ${ }^{15}$ have focused our attention on mesoporous Zr-based MOFs. NU1000 (Scheme 1) consists, in part, of an octahedral $\mathrm{Zr}_{6}$ cluster

Scheme 1. (A) Molecular Representations of NU-1000 and (B) Schematic Representation of Solvent-Assisted Ligand Incorporation (SALI)
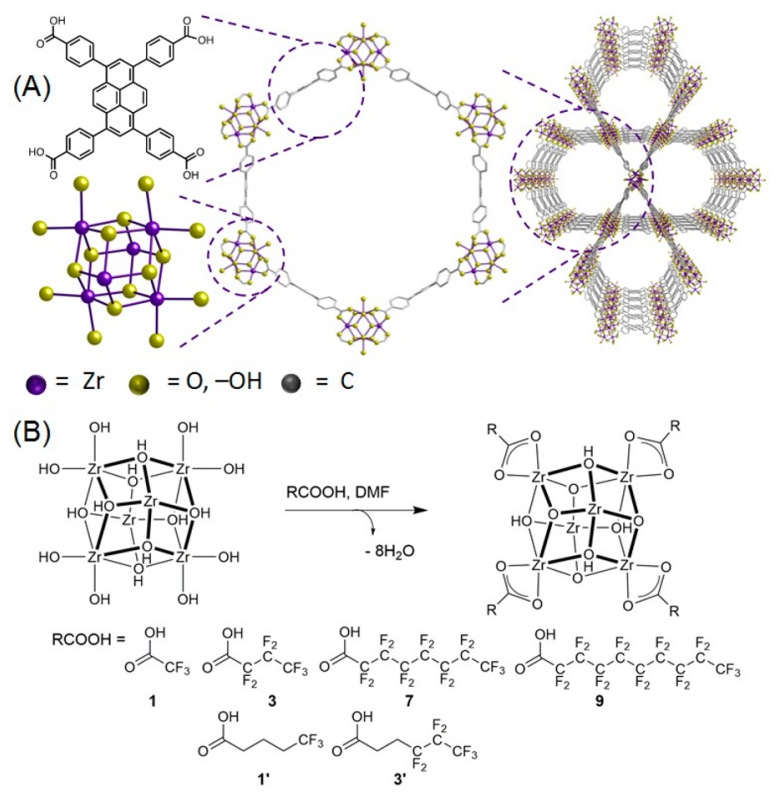

capped by eight $\mu_{3}-\mathrm{OH}$ ligands. ${ }^{16}$ Eight of the 12 octahedral edges are connected to TBAPy linkers $\left(\mathrm{H}_{4} \mathrm{TBAPy}=1,3,6,8\right.$ tetrakis( $p$-benzoic acid)pyrene), while the remaining $\mathrm{Zr}$ coordination sites are occupied by eight terminal $-\mathrm{OH}$ ligands. The resultant MOF has the molecular formula $\mathrm{Zr}_{6}\left(\mu_{3^{-}}\right.$ $\mathrm{OH})_{8}(-\mathrm{OH})_{8}(\mathrm{TBAPy})_{2}$ and contains mesoporous channels lined with terminal $-\mathrm{OH}$ ligands ${ }^{14}(\sim 20-25 \%$ of the mesoporous channels contain a secondary structural element;

Received: August 29, 2013

Published: October 31, 2013 
Table 1. BET Surface Areas, Pore Diameters, Pore Volumes, $\mathrm{CO}_{2}$ Uptake and $Q_{s t}{ }^{0}$ for SALI- $n$ Samples, and NU-1000

\begin{tabular}{|c|c|c|c|c|c|c|c|}
\hline MOF & ligand & $\underset{\mathrm{Zr}_{6}{ }^{a}}{\text { ligand/ }}$ & $\begin{array}{l}\text { BET surface area } \\
\left(\mathrm{m}^{2} / \mathrm{g}\right)\end{array}$ & $\begin{array}{l}\text { BJH pore diameter } \\
(\AA)\end{array}$ & $\begin{array}{l}\text { pore volume } \\
(\mathrm{cc} / \mathrm{g})\end{array}$ & $\begin{array}{c}\mathrm{CO}_{2} \text { uptake @ } 0.15 \text { bar } \\
(\mathrm{cc} / \mathrm{cc})^{c}\end{array}$ & $\begin{array}{c}Q_{\mathrm{st}}^{0} \\
(\mathrm{~kJ} / \mathrm{mol})\end{array}$ \\
\hline NU-1000 & & & 2320 & 31 & 1.4 & 5.6 & 17 \\
\hline SALI-1 & $\mathrm{CF}_{3} \mathrm{CO}_{2}^{-}$ & 4 & 1710 & 30 & 1 & 9.4 & 24 \\
\hline SALI-3 & $\mathrm{CF}_{3}\left(\mathrm{CF}_{2}\right)_{2} \mathrm{CO}_{2}^{-}$ & 3.8 & 1410 & 30 & 0.8 & 8.8 & 28 \\
\hline SALI-7 & $\mathrm{CF}_{3}\left(\mathrm{CF}_{2}\right)_{6} \mathrm{CO}_{2}^{-}$ & 3.7 & 900 & 28 & 0.6 & 7.2 & 31 \\
\hline SALI-9 & $\mathrm{CF}_{3}\left(\mathrm{CF}_{2}\right)_{8} \mathrm{CO}_{2}^{-}$ & 3.4 & 870 & 28 & 0.6 & 6.2 & 34 \\
\hline SALI-1' & $\mathrm{CF}_{3}\left(\mathrm{CH}_{2}\right)_{3} \mathrm{CO}_{2}^{-}$ & 2 & 1600 & 30 & 1 & 6.4 & 21 \\
\hline SALI-3' & $\mathrm{CF}_{3}\left(\mathrm{CF}_{2}\right)_{2}\left(\mathrm{CH}_{2}\right)_{2} \mathrm{CO}_{2}^{-}$ & 3 & 1400 & 30 & 0.9 & 5.3 & 24 \\
\hline
\end{tabular}

${ }^{a}$ See SI section S7. ${ }^{b}$ See SI section S14. ${ }^{c} T=273 \mathrm{~K}$.

see Supporting Information (SI) section S1D), which are attractive for introducing new functionality (vide infra).

In the context of carbon capture and sequestration (CCS), ${ }^{17}$ fluorinated $\mathrm{MOFs}^{18}$ have recently emerged as attractive candidates given their hydrophobicity and the presence of $\mathrm{X}-\mathrm{F}$ dipoles (where, for example, $\mathrm{X}$ can be $\mathrm{C},{ }^{18 \mathrm{~d}, \mathrm{f}} \mathrm{P},{ }^{18 \mathrm{e}} \mathrm{Si}^{18 \mathrm{~b}, \mathrm{c}}$ ). Hydrophobicity should render the MOF stable toward water vapor, ${ }^{18 \mathrm{a}}$ a component in postcombustion $\mathrm{CO}_{2}$ capture, while the presence of $\mathrm{C}-\mathrm{F}$ dipoles should lead to favorable interactions with the quadrupole of $\mathrm{CO}_{2}$ (i.e., high isosteric heats of adsorption, $\left.Q_{\mathrm{st}}\right){ }^{18 \mathrm{f}, 19}$ For example, Eddaoudi has shown an enhancement of $\mathrm{CO}_{2}$ adsorption in MOFs containing $\mathrm{C}-\mathrm{F}$ dipoles in the linker; $Q_{\mathrm{st}}^{0}$ values as high as $60 \mathrm{~kJ} / \mathrm{mol}^{18 \mathrm{t}}$ have been observed. Likewise, MOFs constructed with pyrazine and bipyridine linkers that utilize anionic hexafluorophosphate $^{18 \mathrm{e}}$ and hexafluorosilicate ${ }^{18 \mathrm{~b}}$ as pillars have demonstrated high selectivity for $\mathrm{CO}_{2}$ with moderate to high $Q_{\mathrm{st}}{ }^{0}$ values $(31-45 \mathrm{~kJ} / \mathrm{mol})$.

However, to date, no study has systematically investigated the effects of alkyl $\mathrm{C}-\mathrm{F}$ dipole ${ }^{19 \mathrm{c}}$ on $\mathrm{CO}_{2}$ adsorption. Hence we sought to utilize the $\left[\mathrm{Zr}_{6}\left(\mu_{3}-\mathrm{OH}\right)_{8}(-\mathrm{OH})_{8}\right]^{8+}$ node of NU1000, functioning as a platform for solvent-assisted ligand incorporation (SALI), to introduce perfluoroalkane functionality within its mesoporous channels. Perfluoroalkyl carboxylic acids of varying chain length (1, 3, 7, and 9; Scheme 1) were utilized. Likewise fluoroalkanes bonded to the carboxylic acids via ethylene $\left(\mathrm{CH}_{2}-\mathrm{CH}_{2}\right)$ and propylene $\left(\mathrm{CH}_{2}-\mathrm{CH}_{2}-\mathrm{CH}_{2}\right)$ moieties were utilized to better understand any cooperative $\mathrm{CO}_{2}$ adsorption effects between the perfluoroalkanes and the $\mathrm{Zr}_{6}$ node. Unlike previous metal node functionalization strategies, which utilize dative bonding to coordinatively unsaturated metal sites, ${ }^{20}$ SALI relies on acid-base chemistry between the hydroxyl groups on the NU-1000 node and the carboxylate group of the perfluorinated chain. This results in the introduction of functional groups as charge compensating and strongly bound moieties to the NU-1000 node via ionic bonding. Furthermore, while the nodes of $\mathrm{Zr}$-based MOFs have previously been functionalized with various metals, ${ }^{14,21}$ to our knowledge, this is the first example utilizing the node to introduce carbon-based functionality.

To start, a microcrystalline powder of NU-1000 was synthesized as previously described ${ }^{14}$ and exposed to a $0.1 \mathrm{M}$ solution of fluoroalkyl carboxylic acid (i.e., 8 equiv per $\mathrm{Zr}_{6}$ node) in DMF at $60{ }^{\circ} \mathrm{C}$ for $18-24 \mathrm{~h}$ (see SI for a detailed description). The degree of functionalization was quantified by ${ }^{1} \mathrm{H}$ and ${ }^{19} \mathrm{~F}$ NMR after decomposing the samples in a $10 \%$ $\mathrm{D}_{2} \mathrm{SO}_{4} / \mathrm{DMSO}-d_{6}$ mixture; the ${ }^{19} \mathrm{~F}$ signals of the perfluoroalkanes (1, 3, 7, and 9; Scheme 1) were integrated against the ${ }^{1} \mathrm{H}$ NMR signals of the TBAPy ligand using an internal standard (2,5-dibromo-1,4-bis(trifluoromethyl)benzene; see SI section S6). Approximately 3.4-4 perfluoroalkyl carboxylates, per $\mathrm{Zr}_{6}$ node, can be incorporated within NU-1000 (Table 1). (Complete functionalization considering the SALI stoichiometry shown in Scheme 1 is four carboxylates per $\mathrm{Zr}_{6}$ node; see SI section S7.) We have termed the resultant materials SALI- $n$ (e.g., SALI-1-SALI-9), where $n$ is the carboxylic acid ligand described in Scheme 1. To ensure the maximum accessibility of the $\mathrm{Zr}_{6}$ node by these carboxylates, SALI experiments were carried out at higher temperature $\left(80^{\circ} \mathrm{C}\right)$ and longer times $(36$ h). The degree of functionalization for these extended exposures was the same as those at lower temperature and shorter time (i.e., 4 fluorocarboxylates per $\mathrm{Zr}_{6}$ cluster).

Powder X-ray diffraction (PXRD) measurements (Figure 1A and Figure SI-6) confirmed that the functionalized samples
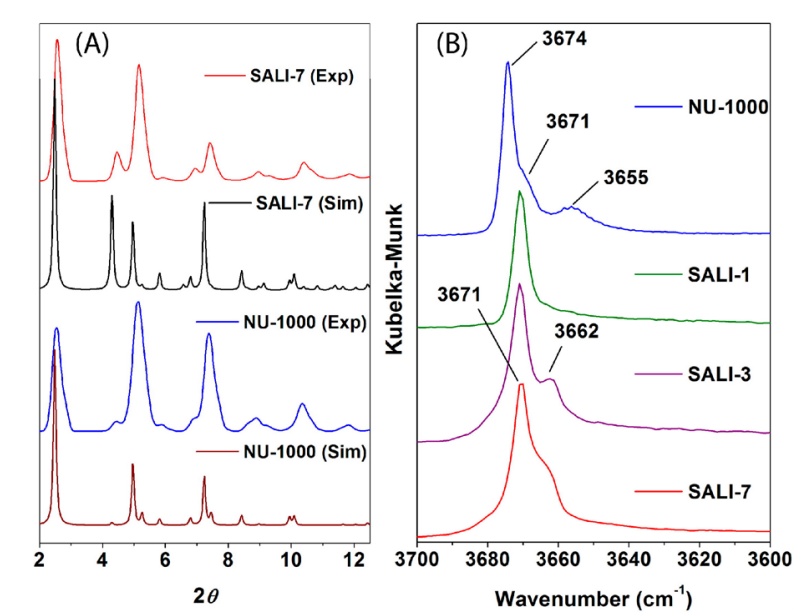

Figure 1. (A) PXRD patterns of NU-1000 simulated (Sim), NU-1000 experimental (Exp), SALI-7 simulated (Sim) from the model structure and SALI-7 (Exp). (B) DRIFTS spectra for NU-1000, SALI-1, SALI3 , and SALI-7.

retain their crystallinity. Note the change in relative intensities of the peaks that appear at $2 \theta$ values of $2.5,4.5$, and 5 upon functionalization. Going from a shorter to longer alkyl chain (e.g., SALI-1 to SALI-9), the intensity of the peak at $2 \theta=4.5$ increases; this change is similar to those observed previously for samples of NU-1000 metalated at the node. ${ }^{14}$ The results can be explained by functionalization occurring at the $\left[\mathrm{Zr}_{6}\left(\mu_{3}\right.\right.$ $\left.\mathrm{OH})_{8}(-\mathrm{OH})\right]^{8+}$ node of NU-1000 (i.e., increased electron density about the 010 plane where a significant portion of the $\mathrm{Zr}_{6}$ node is sited).

Further evidence consistent with functionalization at the node is provided by the results of diffuse reflectance infrared Fourier transform spectroscopy (DRIFTS) measurements. A peak appears at $3674 \mathrm{~cm}^{-1}$ which we assign to terminal $-\mathrm{OH}$ 
groups, while a shoulder at $3671 \mathrm{~cm}^{-1}$ is consistent with the bridging $\mu_{3}-\mathrm{OH}$ groups observed for UiO-66. ${ }^{22}$ For SALI-1, SALI-3, and SALI-7 (Figure 1B), clear disappearance of the sharp peak at $3674 \mathrm{~cm}^{-1}$ indicates that only the terminal $-\mathrm{OH}$ sites are occupied by the fluoroalkyl carboxylates in these functionalized samples, where the peak for the remaining bridging $-\mathrm{OH}$ ligands can be discerned at $3671 \mathrm{~cm}^{-1}$ (also see Figure SI-3). Given that functionalization on the $\mathrm{Zr}_{6}$ node by four carboxylates causes spectral disappearance of all eight terminal $-\mathrm{OH}$ ligands, we postulate that the local coordination environment of the nodes of SALI- $\boldsymbol{n}$ functionalization is similar to that of UiO-66 (Figure 1B). Thus, the added carboxylate ligands in SALI- $\boldsymbol{n}$ compounds coordinate to each of the four equatorial $\mathrm{Zr}^{\mathrm{IV}}$ ions as bidentate ligands, with a resultant molecular formula $\mathrm{Zr}_{6}\left(\mu_{3}-\mathrm{O}\right)_{4}\left(\mu_{3}-\mathrm{OH}\right)_{4}\left(\mathrm{CO}_{2}^{-}\right)_{12}$ (Figure SI-4). Functionalization of NU-1000 with four fluoroalkyl carboxylates involves net removal of eight water molecules (Scheme 1). Notably, the DRIFTS spectrum of SALI-1 in Figure 1B is identical to that of the as-synthesized form of NU-1000, ${ }^{14}$ where, in addition to linkers, the $\mathrm{Zr}_{6}$ cluster of this form features four chelating benzoates (residual modulators).

The $\mathrm{N}_{2}$ adsorption isotherms of the fluoroalkane-functionalized SALI- $\boldsymbol{n}$ samples retain the type IVc shape found for the parent NU-1000. Brunauer-Emmett-Teller (BET) analyses of the isotherms (Figure 2A) indicate a systematic decrease in
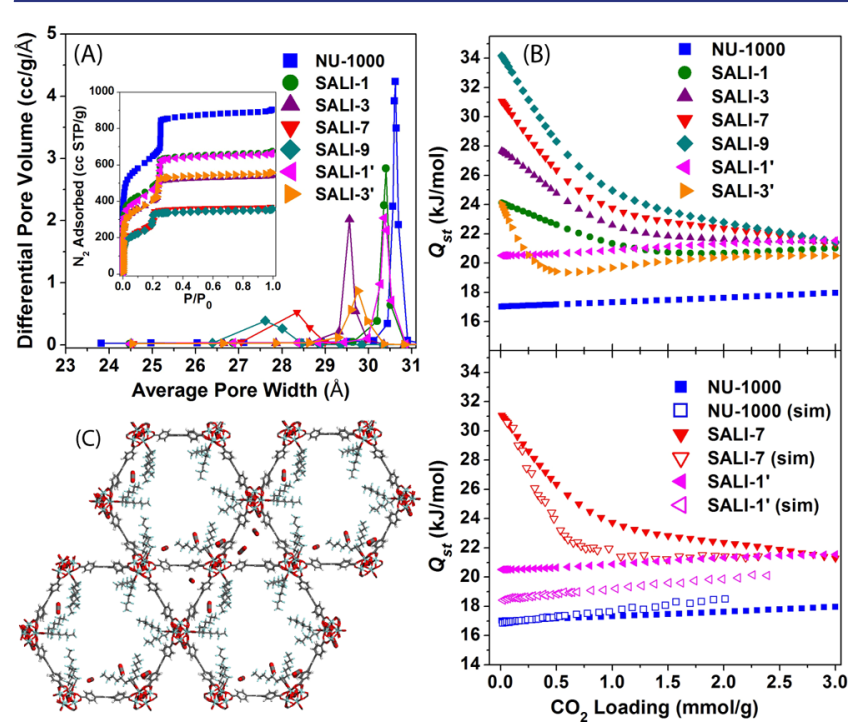

Figure 2. (A) BJH pore size distributions and $\mathrm{N}_{2}$ adsorption isotherms (inset) for NU-1000 and SALI- $\boldsymbol{n}$ samples. (B) $Q_{s t}$ of NU-1000, SALI$\boldsymbol{n}$ and SALI- $\boldsymbol{n}^{\prime}$ samples: (top) calculated from experimental isotherm data and (bottom) comparison of simulated (sim) and experimental $Q_{\text {st }}$ values for selected MOFs. (C) Simulated snapshot of $\mathrm{CO}_{2}$ adsorption depicting the primary $\mathrm{CO}_{2}$ binding sites in SALI-7 $(T=$ $293 \mathrm{~K}$ and $P=0.1 \mathrm{bar}$ ).

surface area from $2320 \mathrm{~m}^{2} \mathrm{~g}^{-1}$ for NU-1000 to 1710 and 870 for SALI-1 and SALI-9. As expected, the gravimetric and volumetric surface areas, along with pore sizes and pore volumes, decrease as a function of chain length. The $\mathrm{CO}_{2}$ adsorption isotherm for NU-1000 shows Langmuir-type behavior with an uptake of $31 \mathrm{cc} / \mathrm{cc}$ at $1 \mathrm{bar}(T=273 \mathrm{~K}$; Figures SI-11 and SI-12). In contrast, the $\mathrm{CO}_{2}$ adsorption profiles (Figures SI-11 and SI-12) for all the SALI- $\boldsymbol{n}$ derivatives show a steeper uptake in the isotherm resulting, in general, higher volumetric uptake (Table 1$)$ at low-pressure $(\sim 0.15$ bar).

In order to estimate the average binding energy of $\mathrm{CO}_{2}$ to the perfluoroalkane-modified samples, we analyzed isotherms collected at different temperatures. Briefly, single-site or dualsite Langmuir models followed by Clausius-Clapeyron analysis were utilized to extract loading-dependent values of $Q_{\text {st }}$ for each compound (Figure $2 \mathrm{~B}$ and Table 1 and SI). In the zero-uptake limit $\left(Q_{s t}{ }^{0}\right)$, all SALI- $\boldsymbol{n}$ samples showed a higher value than unmodified NU-1000, with the value systematically increasing with fluoroalkane chain length. The value of $Q_{\text {st }}{ }^{0}$ for SALI-9 is twice that for unmodified NU-1000. ${ }^{23}$ The $Q_{\text {st }}$ plots for all SALI- $\boldsymbol{n}$ samples show a decrease to $\sim 21 \mathrm{~kJ} / \mathrm{mol}$, which corresponds to the heat of adsorption for the weaker binding sites at higher $\mathrm{CO}_{2}$ loading. For SALI-1 and SALI-9, the $Q_{\text {st }}$ plateaus at a loading of 1.5 and $1.0 \mathrm{mmol} / \mathrm{g}$ of $\mathrm{MOF}$, respectively; these correspond to $\sim 1 \mathrm{CO}_{2}$ per fluoroalkane chain. These findings are consistent with pore confinement playing a crucial role in $\mathrm{CO}_{2}$-sorbent interaction similar to the observations reported by Eddaoudi ${ }^{18 \mathrm{f}}$ and Zhou. ${ }^{24}$ Note that the $Q_{s t}$ values for the SALI- $n$ samples are higher than the enthalpy of liquefaction for $\mathrm{CO}_{2}(17 \mathrm{~kJ} / \mathrm{mol})$ and similar to the $Q_{s t}$ for MOFs with open metal sites such as Co-MOF-74 ${ }^{25}$ and HKUST-1. ${ }^{26}$ To detect possible synergistic effects due to the zirconium-oxo node contributing to the $\mathrm{CF}-\mathrm{CO}_{2}$ interaction, we studied SALI-1' and SALI-3'. Here the fluoroalkane chains are bonded to the carboxylate functionality via an ethylene or propylene moiety (Scheme 1 ). The $Q_{s t}{ }^{0}$ values for both of these SALI- $\boldsymbol{n}^{\prime}$ samples are $\sim 3-4 \mathrm{~kJ} / \mathrm{mol}$ lower than their corresponding perfluoroalkyl counterparts. Additionally, the $Q_{\text {st }}$ plot of SALI-1', as a function of $\mathrm{CO}_{2}$ loading, is similar to that of the unmodified NU-1000 sample, with the exception of slightly higher $Q_{s t}$. These results are in agreement with a recent study reporting synergistic (additive) $Q_{\text {st }}$ effects of polar hexaterbium and hexayttrium nodes for $\mathrm{CO}_{2}$ adsorption within MOFs. ${ }^{18 \mathrm{f}}$

Theoretical modeling confirmed our experimental observations: (1) the simulated $Q_{s t}$ (Figure $2 B$, bottom) for respective model MOFs are in good agreement with the experimental data and (2) primary $\mathrm{CO}_{2}$ binding sites are close to the $\mathrm{Zr}_{6}$ nodes (Figure 2C and Figure SI-19). Though the ideal adsorbed solution theory (IAST) ${ }^{27}$ calculated selectivity for the $\mathrm{CO}_{2}$ adsorption over $\mathrm{N}_{2}\left(\mathrm{CO}_{2} / \mathrm{N}_{2}=10: 90\right)$ was low in these mesoporous MOF structures (see S18), preference for $\mathrm{CO}_{2}$ adsorption increases in the long perfluoroalkyl-functionalized SALI-9 compared to the nonfunctionalized NU-1000. Water adsorption data indicate only modest enhancement in hydrophobicity upon perfluoroalkane functionalization (see S19).

In conclusion, we have developed an efficient functionalization method for Zr-based mesoporous MOFs based on solventassisted ligand incorporation. Spectroscopic data indicate that these carboxylates are bound to the $\mathrm{Zr}_{6}$ node, likely resulting in a UiO-66-type metal node, $\mathrm{Zr}_{6}\left(\mu_{3}-\mathrm{OH}\right)_{4}\left(\mu_{3}-\mathrm{O}\right)_{4}\left(\mathrm{CO}_{2}^{-}\right)_{12}$. $\mathrm{CO}_{2}$ adsorption studies indicate that perfluoroalkane-functionalized nodes in the SALI- $\boldsymbol{n}$ system synergistically act as the primary $\mathrm{CO}_{2}$ binding sites manifesting in systematically higher values for $Q_{s t}$ with increasing chain length. We anticipate that SALI will prove attractive for enhancing chemical competency and functionality within MOFs for a wide variety of applications, including catalysis, sorption, and separations. 


\section{ASSOCIATED CONTENT}

\section{S Supporting Information}

Procedure, characterization, structure modeling, $\mathrm{CO}_{2}$ and water sorption data. This material is available free of charge via the Internet at http://pubs.acs.org.

\section{AUTHOR INFORMATION}

\section{Corresponding Author}

snurr@northwestern.edu; j-hupp@northwestern.edu; o-farha@ northwestern.edu

\section{Notes}

The authors declare no competing financial interest.

\section{ACKNOWLEDGMENTS}

O.K.F., J.T.H., and R.Q.S. gratefully acknowledge support from the Global Climate and Energy Project (GCEP) and U.S. Department of Energy, Office of Science, Basic Energy Sciences Program (Grant DE-FG02-08ER15967). W.B. acknowledges support from the Foundation for Polish Science through the "Kolumb" Program. J.E.M. acknowledges a DOE EERE PD Award, EERE Fuel Cell Technologies Program, administered by ORISE. ORISE is managed by ORAU under DOE Contract DE-AC05-060R23100.

\section{REFERENCES}

(1) (a) Yaghi, O. M.; O’Keefe, M.; Ockwig, N. W.; Chae, H. K.; Eddaoudi, M.; Kim, J. Nature 2003, 423, 705. (b) Férey, G. Chem. Soc. Rev. 2008, 37, 191. (c) Horike, S.; Shimomura, S.; Kitagawa, S. Nat. Chem. 2009, 1, 695.

(2) Farha, O. K.; Eryazici, I.; Jeong, N. C.; Hauser, B. G.; Wilmer, C. E.; Sarjeant, A. A.; Snurr, R. Q.; Nguyen, S. T.; Yazaydın, A. Ö.; Hupp, J. T. J. Am. Chem. Soc. 2012, 134, 15016.

(3) (a) Farha, O. K.; Yazaydın, A. Ö.; Eryazici, I.; Malliakas, C. D.; Hauser, B. G.; Kanatzidis, M. G.; Nguyen, S. T.; Snurr, R. Q.; Hupp, J. T. Nat. Chem. 2010, 2, 944. (b) Zhou, H.-C.; Long, J. R.; Yaghi, O. M. Chem. Rev. 2012, 112, 673.

(4) (a) Ma, L.; Abney, C.; Lin, W. Chem. Soc. Rev. 2009, 38, 1248 (b) Lee, J.; Farha, O. K.; Roberts, J.; Scheidt, K. A.; Nguyen, S. T.; Hupp, J. T. Chem. Soc. Rev. 2009, 38, 1450.

(5) Kreno, L. E.; Leong, K.; Farha, O. K.; Allendorf, M.; Van Duyne, R. P.; Hupp, J. T. Chem. Rev. 2012, 112, 1105.

(6) (a) Sun, L.; Miyakai, T.; Seki, S.; Dincă, M. J. Am. Chem. Soc. 2013, 135, 8185. (b) Jeong, N. C.; Samanta, B.; Lee, C. Y.; Farha, O. K.; Hupp, J. T. J. Am. Chem. Soc. 2012, 134, 51. (c) Horike, S.; Umeyama, D.; Kitagawa, S. Acc. Chem. Res. 2013, DOI: 10.1021/ ar300291s.

(7) (a) Jin, S.; Son, H.-J.; Farha, O. K.; Wiederrecht, G. P.; Hupp, J. T. J. Am. Chem. Soc. 2013, 135, 955. (b) Son, H.-J.; Jin, S.; Patwardhan, S.; Wezenberg, S. J.; Jeong, N. C.; So, M.; Wilmer, C. E.; Sarjeant, A. A.; Schatz, G. C.; Snurr, R. Q.; Farha, O. K.; Wiederrecht, G. P.; Hupp, J. T. J. Am. Chem. Soc. 2013, 135, 862. (c) Kent, C. A.; Mehl, B. P.; Ma, L.; Papanikolas, J. M.; Meyer, T. J.; Lin, W. J. Am. Chem. Soc. 2010, $132,12767$.

(8) Cohen, S. M. Chem. Rev. 2012, 112, 970.

(9) (a) Hwang, Y. K.; Hong, D.-Y.; Chang, J.-S.; Jhung, S. H.; Seo, Y.K.; Kim, J.; Vimont, A.; Daturi, M.; Serre, C.; Férey, G. Angew. Chem., Int. Ed. 2008, 47, 4144. (b) Farha, O. K.; Mulfort, K. L.; Hupp, J. T. Inorg. Chem. 2008, 47, 10223. (c) Seo, J. S.; Whang, D.; Lee, H.; Jun, S. I.; Oh, J.; Jeon, Y. J.; Kim, K. Nature 2000, 404, 982.

(10) Kiang, Y.-H.; Gardner, G. B.; Lee, S.; Xu, Z.; Lobkovsky, E. B. J. Am. Chem. Soc. 1999, 121, 8204.

(11) (a) Bury, W.; Fairen-Jimenez, D.; Lalonde, M. B.; Snurr, R. Q.; Farha, O. K.; Hupp, J. T. Chem. Mater. 2013, 25, 739. (b) Karagiaridi, O.; Bury, W.; Sarjeant, A. A.; Stern, C. L.; Farha, O. K.; Hupp, J. T. Chem. Sci. 2012, 3, 3256. (c) Karagiaridi, O.; Lalonde, M. B.; Bury, W.; Sarjeant, A. A.; Farha, O. K.; Hupp, J. T. J. Am. Chem. Soc. 2012, 134,
18790. (d) Takaishi, S.; DeMarco, E. J.; Pellin, M. J.; Farha, O. K.; Hupp, J. T. Chem. Sci. 2013, 4, 1509. (e) Li, T.; Kozlowski, M. T.; Doud, E. A.; Blakely, M. N.; Rosi, N. L. J. Am. Chem. Soc. 2013, 135, 11688. (f) Kim, M.; Cahill, J. F.; Su, Y.; Prather, K. A.; Cohen, S. M. Chem. Sci. 2012, 3, 126. (g) Burnett, B. J.; Barron, P. M.; Hu, C.; Choe, W. J. Am. Chem. Soc. 2011, 133, 9984.

(12) Cavka, J. H.; Jakobsen, S.; Olsbye, U.; Guillou, N.; Lamberti, C.; Bordiga, S.; Lillerud, K. P. J. Am. Chem. Soc. 2008, 130, 13850.

(13) Wu, H.; Yildirim, T.; Zhou, W. J. Phys. Chem. Lett. 2013, 4, 925.

(14) Mondloch, J. E.; Bury, W.; Fairen-Jimenez, D.; Kwon, S.; DeMarco, E. J.; Weston, M. H.; Sarjeant, A. A.; Nguyen, S. T.; Stair, P. C.; Snurr, R. Q.; Farha, O. K.; Hupp, J. T. J. Am. Chem. Soc. 2013, 135, 10294

(15) (a) Morris, W.; Volosskiy, B.; Demir, S.; Gándara, F.; McGrier, P. L.; Furukawa, H.; Cascio, D.; Stoddart, J. F.; Yaghi, O. M. Inorg. Chem. 2012, 51, 6443. (b) Feng, D.; Gu, Z.-Y.; Li, J.-R.; Jiang, H.-L.; Wei, Z.; Zhou, H.-C. Angew. Chem., Int. Ed. 2012, 51, 10307. (c) Chen, Y.; Hoang, T.; Ma, S. Inorg. Chem. 2012, 51, 12600.

(16) An alternative formulation of the NU-1000 structure would feature oxo and aquo ligands in place of hydroxo ligands. Either formulation can yield the subsequently observed ligand incorporation chemistry. For simplicity, we will henceforth refer only to the hydroxo alternative.

(17) (a) Li, J.-R.; Sculley, J.; Zhou, H.-C. Chem. Rev. 2012, 112, 869. (b) Sumida, K.; Rogow, D. L.; Mason, J. A.; McDonald, T. M.; Bloch, E. D.; Herm, Z. R.; Bae, T.-H.; Long, J. R. Chem. Rev. 2012, 112, 724. (c) Liu, J.; Thallapally, P. K.; McGrail, B. P.; Brown, D. R.; Liu, J. Chem. Soc. Rev. 2012, 41, 2308.

(18) (a) Yang, C.; Kaipa, U.; Mather, Q. Z.; Wang, X.; Nesterov, V.; Venero, A. F.; Omary, M. A. J. Am. Chem. Soc. 2011, 133, 18094. (b) Nugent, P.; Belmabkhout, Y.; Burd, S. D.; Cairns, A. J.; Luebke, R.; Forrest, K.; Pham, T.; Ma, S.; Space, B.; Wojtas, L.; Eddaoudi, M.; Zaworotko, M. J. Nature 2013, 495, 80. (c) Kanoo, P.; Reddy, S. K.; Kumari, G.; Haldar, R.; Narayana, C.; Balasubramanian, S.; Maji, T. K. Chem. Commun. 2012, 48, 8487. (d) Wilmer, C. E.; Farha, O. K.; Bae, Y.-S.; Hupp, J. T.; Snurr, R. Q. Energy Environ. Sci. 2012, 5, 9849. (e) Noro, S.-i.; Hijikata, Y.; Inukai, M.; Fukushima, T.; Horike, S.; Higuchi, M.; Kitagawa, S.; Akutagawa, T.; Nakamura, T. Inorg. Chem. 2013, 52, 280. (f) Xue, D.-X.; Cairns, A. J.; Belmabkhout, Y.; Wojtas, L.; Liu, Y.; Alkordi, M. H.; Eddaoudi, M. J. Am. Chem. Soc. 2013, 135, 7660. (g) Fernandez, C. A.; Thallapally, P. K.; Motkuri, R. K.; Nune, S. K.; Sumrak, J. C.; Tian, J.; Liu, J. Cryst. Growth Des. 2010, 10, 1037.

(19) (a) DeSimone, J. M.; Maury, E. E.; Menceloglu, Y. Z.; McClain, J. B.; Romack, T. J.; Combes, J. R. Science 1994, 265, 356. (b) Fried, J. R.; Hu, N. Polymer 2003, 44, 4363. (c) Dalvi, V. H.; Srinivasan, V.; Rossky, P. J. J. Phys. Chem. C 2010, 114, 15553.

(20) (a) McDonald, T. M.; D’Alessandro, D. M.; Krishna, R.; Long, J. R. Chem. Sci. 2011, 2, 2022. (b) Zheng, S.-T.; Zhao, X.; Lau, S.; Fuhr, A.; Feng, P.; Bu, X. J. Am. Chem. Soc. 2013, 135, 10270.

(21) Larabi, C.; Quadrelli, E. A. Eur. J. Inorg. Chem. 2012, 2012, 3014.

(22) Valenzano, L.; Civalleri, B.; Chavan, S.; Bordiga, S.; Nilsen, M. H.; Jakobsen, S.; Lillerud, K. P.; Lamberti, C. Chem. Mater. 2011, 23, 1700.

(23) The observed large differences in $Q_{\mathrm{st}}{ }^{0}$ values for $\mathrm{CO}_{2}$ uptake by various SALI- $\boldsymbol{n}$ materials versus NU-1000 imply that affinity constants from fits of the corresponding $\mathrm{CO}_{2}$ sorption isotherms should be 1 to 3 orders of magnitude larger for the SALI- $\boldsymbol{n}$ materials than for NU1000. As shown in the SI, these expectations are indeed borne out.

(24) Li, J.-R.; Yu, J.; Lu, W.; Sun, L.-B.; Sculley, J.; Balbuena, P. B.; Zhou, H.-C. Nat. Commun. 2013, 4, 1538.

(25) Caskey, S. R.; Wong-Foy, A. G.; Matzger, A. J. J. Am. Chem. Soc. 2008, 130, 10870.

(26) Wang, Q. M.; Shen, D.; Bülow, M.; Lau, M. L.; Deng, S.; Fitch, F. R.; Lemcoff, N. O.; Semanscin, J. Microporous Mesoporous Mater. 2002, 55, 217.

(27) Myers, A. L.; Prausnitz, J. M. AlChE J. 1965, 11, 121. 